\title{
The role of neurotensin as a novel biomarker in the endoscopic screening of high-risk population for developing colorectal neoplasia
}

\author{
Christos Kontovounisios ${ }^{1,2} \cdot$ Shengyang Qiu $^{2}$ (1) $\cdot$ Shahnawaz Rasheed ${ }^{1,2} \cdot$ \\ Ara Darzi $^{1,2} \cdot$ Paris Tekkis $^{1,2}$
}

Received: 31 August 2016/Accepted: 4 May 2017/Published online: 30 May 2017

(c) The Author(s) 2017. This article is an open access publication

\begin{abstract}
Colorectal cancer screening programs aim at early detection of cancer to reduce incidence rates and mortality. The objective of this study is to identify the role of neurotensin in the endoscopic screening of high-risk population for developing colorectal neoplasia. Blood samples from patients referred for urgent colonoscopy to investigate symptoms suspicious of colorectal cancer were collected. Blood neurotensin levels were measured using enzyme-linked immunosorbent assay. Colonoscopy findings were used as reference for determining the diagnostic accuracy of blood neurotensin. The study comprised 26 patients in total: 12 healthy and 14 with colon pathology (13 high-grade dysplasia adenomatous polyps, 1 adenocarcinoma). There were no statistically significant differences in the clinical and biochemical parameters between colon pathology and healthy group except neurotensin levels. Pathology in colon was associated with 3.7-fold increase in NT levels. In multivariate analysis, patients with pathology in colon have increased serum neurotensin levels compared to controls adjusted for age, gender, BMI and co-morbidities. The value of $12.93 \mathrm{pg} / \mathrm{ml}$ is associated with $87.5 \%$ sensitivity and $91.7 \%$ specificity for discriminating the colon pathology from normal colonic epithelium $(p=0.001)$. Neurotensin plasma values differentiate healthy people from patients suffering from colonic
\end{abstract}

Shengyang Qiu

s.qiu@imperial.ac.uk

1 Department of Colorectal Surgery, The Royal Marsden Hospital, Chelsea, London, UK

2 Department of Surgery and Cancer, Imperial College London, Chelsea and Westminster Hospital Campus, London, UK pathologies such as adenomatous polyps and cancer. The use of neurotensin as a potential endoscopic screening tool for identifying high-risk population for developing colorectal cancer is promising, but much has to be done before it is validated in larger scale prospective studies.

Keywords Colorectal cancer - Diagnostic biomarker . Neurotensin

\section{Introduction}

Colorectal cancer (CRC) is a worldwide health problem that ranks third in incidence and fourth in mortality with an estimated 1.2 million cases and 0.6 million deaths annually $[1,2]$. Mortality can be lowered by both early diagnosis and cancer prevention where the objective of screening is to detect cancer at an early curable stage. The European Union (EU) recommendations for CRC screening is based on tests with quality assurance for the diagnosis and management of patients with screen-detected lesions. In countries with a serious burden of $\mathrm{CRC}$, screening promotes cancer control, provided the services are of high quality. Conventional screening tools include Digital Rectal Examination, Faecal Occult Blood Test (FOBT), Sigmoidoscopy, Colonoscopy, Virtual Colonoscopy and Double Contrast Barium Enema (DCBE). Studies have shown that patients over the age of 60 having had a normal colonoscopy can be followed with FOBT or computerized tomography (CT) pneumocolon every 5 years. This screening process can provide overall the same survival benefit with less morbidity and cost [3]. Colonoscopic surveillance is considered the gold standard in detecting colonic malignancy compared to FOBT; however, low participation rate has questioned its benefit [4]. 
The last decades have been marked by the accumulation of knowledge about the inner workings of the normal and cancer cell. The discovery and validation of new targets are the foundation and the source of new screening modalities; therefore, efforts have been made to identify blood-based markers for the early detection of CRC. The availability of blood-based, non-invasive tests promises to improve screening compliance and to reduce the morbidity and mortality associated with this malignancy.

Neurotensin (NT) is a 13-amino-acid peptide originally isolated from extracts of bovine hypothalami in 1973 by Carraway and Leeman [5]. The biological effects of NT are known to be through three receptors, two G protein-coupled receptors, neurotensin receptor 1 (NTSR1) and receptor 2 (NTSR2), and a single transmembrane domain sorting receptor 3 (NTSR3) [6, 7]. NT has shown to exert numerous oncogenic effects involved in tumour growth and metastatic spread. These effects are mostly mediated by NTSR1, making the NT/NTSR1 complex an actor in cancer progression. Colorectal cancers are known to possess NT receptors and some produce also NT peptide. Yoshinaga et al. have demonstrated that administration of NT significantly increases mean tumour size, weight and deoxyribonucleic acid (DNA), ribonucleic acid (RNA) and protein contents of the murine colon cancer cell line MC26 [8]. Other studies have demonstrated that the use of NT receptor antagonist have inhibitory effect on human colon cancer cell (LoVo) growth [9] and in cells xenografted into nude mice [10]. In human CRC, NTSR1 was expressed in increasing amounts in adenomas and adenocarcinomas, respectively [11].

Therefore, NT/NTSR1 expression may be involved in the early stages of colonic carcinogenesis and thus could potentially be an additional non-invasive screening tool [12]. At the same time, its non-invasiveness advantage may lead to high-population compliance at a lower cost than the current screening system and with the capacity for early detection of CRC and precursor adenomatous polyps.

This pilot study aimed to investigate whether patients with CRC have a specific pattern of serum NT values compared with healthy controls and determine the feasibility of this factor being used as an additional diagnostic and screening tool for colorectal pathology.

\section{Materials and methods}

The study was conducted in 2015 at Royal Marsden Hospital (RMH) and Chelsea and Westminster Hospital $(\mathrm{C} \& \mathrm{~W})$ and was approved by the NHS Research Ethics Committee. Patients referred for colonoscopic screening/diagnostic colonoscopy at the endoscopy departments of $\mathrm{RMH}$ and $\mathrm{C} / \mathrm{W}$ were prospectively enrolled following receipt of written informed consent, in adherence with local ethics guidelines.

Inclusion criteria were: (1) patients aged 18 years or older, (2) patients referred for colonoscopy under the National Health Service (NHS) Urgent Suspected Colorectal Cancer pathway, (3) patients able to give informed consent. Exclusion criteria were: (1) patients who were pregnant, lactating, or undergoing fertility treatment, (2) patients with known active inflammation or infection or an autoimmune disorder, including inflammatory bowel diseases, (3) patients with known malignancy, (4) patients receiving immunosuppressive treatment or chemotherapy.

For each patient, $5 \mathrm{ml}$ of blood was collected from a peripheral vein 15-30 min prior to participants undergoing colonoscopy. The whole blood was separated into plasma using EDTA as an anticoagulant. Samples were assigned a random sample ID and then centrifuged for $15 \mathrm{~min}$ at 1000 relative centrifugal force at $2-8{ }^{\circ} \mathrm{C}$ within $30 \mathrm{~min}$ of collection. The plasma was collected and immediately stored in a $-80{ }^{\circ} \mathrm{C}$ freezer.

A competitive enzyme immunoassay (ELISA) kit was used to detect neuropeptide $\mathrm{Y}$ peptide according to the manufacturer's instructions (CUSABIO). This assay utilizes the quantitative sandwich enzyme immunoassay technique. Antibody specific for NT has been pre-coated on to a microplate. Standards and samples were pipetted into the wells and any NT present was bound by the immobilized antibody. After removing any unbound substances, a biotin-conjugated antibody specific for NT was added to the wells. After washing, avidin-conjugated horseradish peroxidase (HRP) was added to the wells. Following a wash to remove any unbound avidin-enzyme reagent, a substrate solution was added to the wells and colour developed in proportion to the amount of NT bound in the initial step. The colour development was stopped and the intensity of the colour was measured using an ELISA microplate reader. The optical density (OD) absorbance was set at $450 \mathrm{~nm}$ within $30 \mathrm{~min}$ of adding the stop solution. A standard curve was plotted for OD vs. the respective concentration of the standard solutions. The NT concentration $(\mathrm{pg} / \mathrm{ml})$ of each sample was extrapolated from the standard curve.

To minimize bias, the colonoscopy findings from each subject were only reviewed after the completion of the ELISA. The colonoscopy results were reviewed by a member of the team (C.K.). The primary outcome of interest was the presence of colorectal polyps, cancers and other significant pathologies detected by colonoscopy. The NT concentration from each blinded sample is matched to the colonoscopy result to allow statistical analysis. 


\section{Statistical analysis}

Statistically significant values were considered if $p<0.05$. Data were presented as mean \pm standard error of the mean for quantitative variables and as $n(\%)$ for qualitative. For quantitative variables, Chi-squared with Fisher's exact test was used. Test for normal assumption was performed with Shapiro-Wilk test for quantitative variables. Following the normal assumption, it was tested with Student's $t$ test and if this was not the case we used non-parametric MannWhitney $U$ test. For multivariate analysis, linear regression was used with dependent variable being the level of NT. A receiver operating characteristic (ROC) was used to summarize the performance of two classes among the range of possible variables to establish which value of neurotensin can be used as discriminator between two groups with sufficient sensitivity and specificity.

The Statistical Package for the Social Sciences (SPSS) version 20 was used for data analysis.

\section{Results}

The study population comprised 26 patients in total: 12 control/healthy subjects with no abnormality or dysplasia on colonoscopy and 14 with colon pathology (13 with high-grade dysplasia adenomatous polyps, 1 with adenocarcinoma). In descriptive analysis, the mean age in years was 55.42, the mean BMI 24, 87 and mean NT level $24 \mathrm{pg} /$ $\mathrm{ml}$. There were no statistically significant differences in the clinical and biochemical parameters between colon pathology group and healthy group. The only significant difference was in neurotensin levels. Pathology in colon was associated with 3.7-fold increase in NT levels (Table 1). In multivariate analysis, patients with pathology in colon have increased serum neurotensin levels compared to controls adjusted for age, gender, BMI and co-morbidities (Table 2). The value of $12.93 \mathrm{pg} / \mathrm{ml}$ is associated with $87.5 \%$ specificity and $91.7 \%$ specificity for discriminating the colon pathology from normal colonic epithelium. The ROC curve was found to be statistically significant $(\mathrm{AUC}=0.893,95 \%$ CI $0.749-1, p=0.001$ ) (Fig. 1).

\section{Discussion and conclusion}

Currently, 136,830 new cases of colorectal cancer (CRC) and 50,310 deaths due to CRC have been estimated in the United States in 2014. In the European Union (EU), colorectal cancer is the third most common cancer and the second leading cause of death, accounting for more than 345,000 new cases and 150,000 deaths in 2012.
Table 1 Characteristics and average blood neurotensin levels of patients who had normal colonoscopy vs. patients with colon pathologies (polyps and cancer)

\begin{tabular}{|c|c|c|c|c|c|c|}
\hline & \multicolumn{5}{|c|}{ Group } & \multirow[t]{3}{*}{$p$ value } \\
\hline & \multicolumn{2}{|c|}{ Normal } & \multicolumn{3}{|c|}{ Colon pathology } & \\
\hline & $N$ & $N \%$ & $N$ & & & \\
\hline \multicolumn{7}{|l|}{ Gender } \\
\hline Female & 9 & 75.0 & 7 & \multicolumn{2}{|c|}{50.0} & $\mathrm{n} . \mathrm{s}^{+}$ \\
\hline Male & 3 & 25.0 & 7 & \multicolumn{2}{|c|}{50.0} & \\
\hline \multicolumn{6}{|c|}{ Co-morbidities } & \\
\hline No & 9 & 75.0 & 9 & \multicolumn{2}{|c|}{64.3} & $\mathrm{n} . \mathrm{s}^{+}$ \\
\hline Yes & 3 & 25.0 & 5 & \multicolumn{2}{|c|}{35.7} & \\
\hline \multicolumn{7}{|l|}{ Smoker } \\
\hline No & 11 & 91.7 & 12 & \multicolumn{2}{|c|}{85.7} & \\
\hline Yes & 1 & 8.3 & 2 & \multicolumn{2}{|c|}{14.3} & $\mathrm{n} . \mathrm{s}^{+}$ \\
\hline \multicolumn{7}{|c|}{ Alcohol consumption } \\
\hline No & 12 & 100.0 & 11 & \multicolumn{2}{|c|}{78.6} & \\
\hline \multirow[t]{2}{*}{ Yes } & 0 & 0.0 & 3 & \multicolumn{2}{|c|}{21.4} & $\mathrm{n} . \mathrm{s}^{+}$ \\
\hline & & Mean & SEM & Mean & SEM & $p$ value \\
\hline Age (years) & & 53.92 & 5.46 & 26.71 & 3.78 & n.s* \\
\hline BMI $\left(\mathrm{kg} / \mathrm{m}^{2}\right)$ & & 22.23 & 1.41 & 26.26 & 1.00 & n.s* \\
\hline Neurotensin & $\mathrm{pg} / \mathrm{ml})$ & 9 & 1 & 37 & 6 & $<0.001 *$ \\
\hline
\end{tabular}

$B M I$ body mass index, $S E M$ standard error of mean, $\mathrm{pg} / \mathrm{ml}$ picograms per millilitre

+ Chi-square/Fisher's exact test, * Mann-Whitney $U$ test

Survivorship is highly dependent at the time of diagnosis since early tumour stage has better therapeutic outcomes. Therefore, early detection of CRC can improve the 5-year survival rate from about $10 \%$ up to $90 \%$ [13].

The gold standard screening test, colonoscopy, is considered to be invasive and the rate of non-compliance among population is $40 \%$ or higher [14]. The faecal occult blood test and faecal immune test are currently the approved non-invasive screening methods, with $60-80 \%$ sensitivity and 85-95\% specificity [15]. Other blood markers such as carcinoembryonic antigen (CEA) and cancer antigen (CA) 19-9 have lower sensitivity and/or specificity [16]. These markers are predominantly used in the surveillance of colorectal cancer patients but their low screening sensitivity and specificity has excluded from the screening recommendations. Promising results have been published for genes deriving from peripheral blood mononuclear cells (PBMCs) including DNA methylation of specific genes, but more extensive experiments are required to validate their results $[17,18]$. Therefore, the combination of the absence of symptoms in early stages of disease, the invasive nature of the gold standard colonoscopy, and the low specificity and sensitivity of faecal blood tests results in late diagnosis of disease with severe 
Table 2 Multivariate regression analysis of effect of the presence of colorectal pathology and other patient factors on increased serum NT levels

\begin{tabular}{lcll}
\hline & OR & $95 \%$ CI & $p$ value \\
\hline Group & & & \\
Colorectal pathology vs. normal & 26.17 & 12.47 to 39.271 & 0.001 \\
Age (years) & 0.341 & -0.108 to 0.79 & n.s \\
Gender & & & \\
Female vs. male & 5.742 & -8.8 to 20.28 & n.s \\
BMI $\left(\mathrm{kg} / \mathrm{m}^{2}\right.$ ) & -0.454 & -2.2 to 1.2 & $\mathrm{n} . \mathrm{s}$ \\
Co-morbidities & & & $\mathrm{n} . \mathrm{s}$ \\
$\quad$ Yes vs. no & 6.128 & -9.27 to 21.53 & \\
\hline
\end{tabular}

OR odds ratio, $95 \%$ CI 95\% confidence intervals, BMI body mass index

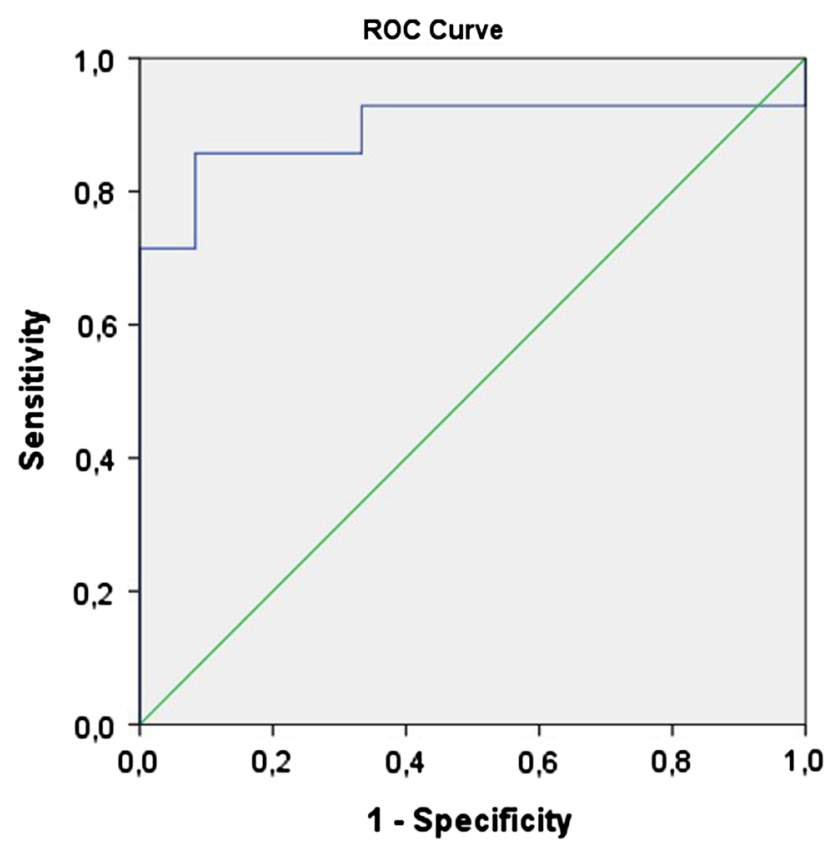

Fig. 1 Received operator characteristics (ROC) curve for the sensitivity and specificity of plasma neurotensin level in identifying colorectal polyps and cancer

burden on patient's management and in National Health system (NHS) costs.

The ideal marker should have the following qualities:

(a) High sensitivity and specificity.

(b) Safe and non-invasive so that it can be broadly accepted by patients.

(c) Cost effective so that it can be accepted by NHS.

(d) Easy to measure.

(e) Should be detected among genders and ethnic groups [19-21].

With the limited suitability of CEA and CA19-9, several candidate proteins have been published as CRC diagnostic markers. A single protein marker, TIMP-1, has detected CRC with $42-65 \%$ sensitivity and 95\% specificity [22]. Babel et al. reported 43 proteins that could distinguish between CRC patients and healthy controls [23].

The role of NT in CRC is proven in the laboratory setting. Poinot-Chazel et al. has published a mechanism by which NT promotes cell growth in Chinese Hamster Ovary (CHO) cells transformed with human NTRS1 and in colon cancer HT29 cells. He suggested that growth stimulation by NT could involve the coupling of NT receptor to Krox24 induction via the MAP kinase cascade. This hypothesis is also favoured since Krox-24 is an early response gene producing a zinc-finger transcription factor that targets several genes involved in cell division [24].

Maoret et al. found that administration of NT can stimulate growth in five different human cancer lines (SW480, SW620, HT29, HCT116 and C1.19A) that express NTSR1, but has no effect on cells with absent NTSR1. In SW480 cell lines, NT increased colony formation by approximately $50 \%$ [10].

Gui et al. [11] examined NTSR1 mRNA by in situ hybridization in normal colonic mucosa, adenomas and colonic adenocarcinomas. NTSR1 mRNA expression was found to be non-detectable in epithelial cells of normal colonic epithelium but adenomas and adenocarcinomas demonstrated moderate to strong expression $(p<0.05)$. There was higher level of expression in adenocarcinomas compared to adenomas $(p<0.05)$. The intensity of NTSR 1 expression was higher in cases where tumour was present in muscularis propria or even gone beyond that layer. On the other hand, expression was less in cases where tumour was localised in the mucosa and submucosa.

Souaze et al. validated the Wnt/APC signalling pathway on the NT1 receptor promoter activation and showed that NT1 receptor gene activation was related to nuclear or cytoplasmic beta-catenin localization. NT1 receptor was absent when beta-catenin was identified in early adenomas of patients with familial adenomatous polyposis, hereditary non-polyposis colorectal cancer and loss of heterozygosity tumours [25].

Sgourakis et al. demonstrated the use of serum NT and interleukin 8 (IL-8) values as a screening tool for colorectal 
cancer. Fifty-six patients and 15 healthy controls were divided to seven groups according to their disease presentation. Neurotensin $(p=0.004)$ and IL-8 $(p=0.029)$ differed between healthy and colorectal cancer patients. Neurotensin values differentiate the control group from all other groups. The value of plasma NT $\leq 54.47 \mathrm{pg} / \mathrm{ml}$ at presentation selected by receiver ROC curves demonstrated a sensitivity of $77 \%$, specificity of $90 \%$, and an estimate of area under ROC curve of $85 \%$ in diagnosing colorectal cancer. This finding is similar to those reported here. Furthermore, it suggests IL- 8 should be used complementary to neurotensin due to its lower specificity [26].

In this pilot study, the majority in the colon pathology group were high-grade dysplasia adenomatous polyps, 13/14 patients, which was associated with 3.7-fold increase in NT levels. The value of $12.93 \mathrm{pg} / \mathrm{ml}$ is associated with $87.5 \%$ sensitivity and $91.7 \%$ specificity for discriminating the colon pathology from normal colonic epithelium. To our knowledge, this is one of the first studies to measure plasma neurotensin in humans with the aim of providing a screening system for colorectal cancer by bridging basic research with clinical practice. Our values of neurotensin in adenomatous polyps are lower compared to higher values of other studies which measured NT in adenocarcinoma.

The sample size of this study is small and there is no doubt larger scale studies are required to validate the findings reported here. An inclusion of larger number of CRC patients will also answer the question of whether blood NT level can be used to differentiate cases of colorectal polyps and cancers. In this study, the analysis of the NTSR1 receptor was not performed. These measurements are also pending along with prospective validation of our results which has not yet been applied. Only a single measurement per patient was calculated, but we plan to perform a second measurement in the future. Further to diagnosis and screening, blood tumour markers may also be relevant in the prognosis of CRC $[27,28]$.

Neurotensin plasma values appeared to differentiate healthy people from patients suffering from colonic pathologies such as adenomatous polyps and cancer, but much has to be done before it is validated in larger scale prospective studies.

Acknowledgements The authors thank the National Institute of Health Research Imperial Biomedical Research Centre for their support.

Author contributions CK, SQ and PT analysed and interpreted the patient data and collected patient samples. CK performed the ELISA examination of the blood. CK, SQ, PT, SR and AD were major contributors in writing the manuscript. All authors read and approved the final manuscript.

\section{Compliance with ethical standards}

Conflict of interest The authors declare that they have no competing interests.

Ethical approval The study was carried out in compliance with ethical standards. Ethics approval and consent was granted by East of Scotland Research Ethics Service (EoSRES) REC 2 (Reference 14/ES/1042).

Informed consent All participants have given informed consent prior to taking part in the study.

Availability of data and materials The datasets used and/or analysed in the current study are available from the corresponding author on reasonable request.

Funding The research project consumable costs are funded by the NIHR Imperial BRC. There is no other source of funding. The funder did not contribute towards the design of the study and collection, analysis and interpretation of data, and in writing the manuscript.

Open Access This article is distributed under the terms of the Creative Commons Attribution 4.0 International License (http://crea tivecommons.org/licenses/by/4.0/), which permits unrestricted use, distribution, and reproduction in any medium, provided you give appropriate credit to the original author(s) and the source, provide a link to the Creative Commons license, and indicate if changes were made.

\section{References}

1. Atkin WS, Valori R, Kuipers EJ, Hoff G, Senore C, Segnan N, Jover R, Schmiegel W, Lambert R, Pox C (2012) European guidelines for quality assurance in colorectal cancer screening and diagnosis. First Edition-colonoscopic surveillance following adenoma removal. Endoscopy 44 Suppl 3:SE151-SE163

2. Favoriti P, Carbone G, Greco M, Pirozzi F, Pirozzi REM, Corcione $\mathrm{F}$ (2016) Worldwide burden of colorectal cancer: a review. Updates Surg 68:7-11

3. Knudsen AB, Hur C, Gazelle GS, Schrag D, McFarland EG, Kuntz KM (2012) Rescreening of persons with a negative colonoscopy result: results from a microsimulation model. Ann Intern Med 157:611-620

4. Hassan C, Giorgi Rossi P, Camilloni L, Rex DK, Jimenez-Cendales B, Ferroni E, Borgia P, Zullo A, Guasticchi G (2012) Metaanalysis: adherence to colorectal cancer screening and the detection rate for advanced neoplasia, according to the type of screening test. Aliment Pharmacol Ther 36:929-940

5. Carraway R, Leeman SE (1973) The isolation of a new hypotensive peptide, neurotensin, from bovine hypothalami. J Biol Chem 248:6854-6861

6. Vincent JP, Mazella J, Kitabgi P (1999) Neurotensin and neurotensin receptors. Trends Pharmacol Sci 20:302-309

7. Mazella J, Vincent JP (2006) Functional roles of the NTS2 and NTS3 receptors. Peptides 27:2469-2475

8. Yoshinaga K, Evers BM, Izukura M, Parekh D, Uchida T, Townsend CM Jr, Thompson JC (1992) Neurotensin stimulates growth of colon cancer. Surg Oncol 1:127-134

9. Iwase K, Evers BM, Hellmich MR, Kim HJ, Higashide S, Gully D, Townsend CM Jr (1996) Indirect inhibitory effect of a neurotensin receptor antagonist on human colon cancer (LoVo) growth. Surg Oncol 5:245-251 
10. Maoret JJ, Anini Y, Rouyer-Fessard C, Gully D, Laburthe M (1999) Neurotensin and a non-peptide neurotensin receptor antagonist control human colon cancer cell growth in cell culture and in cells xenografted into nude mice. Int J Cancer 80:448-454

11. Gui X, Guzman G, Dobner PR, Kadkol SS (2008) Increased neurotensin receptor-1 expression during progression of colonic adenocarcinoma. Peptides 29:1609-1615

12. Qiu S, Pellino G, Fiorentino F, Rasheed S, Darzi A, Tekkis P, Kontovounisios C (2017) A review of the role of neurotensin and its receptors in colorectal cancer. Gastroenterol Res Pract 2017:6456257

13. Siegel R, Ma J, Zou Z, Jemal A (2014) Cancer statistics. CA Cancer J Clin 64:9-29

14. Shapiro JA, Klabunde CN, Thompson TD, Nadel MR, Seeff LC, White A (2012) Patterns of colorectal cancer test use, including CT colonography, in the 2010 National Health Interview Survey. Cancer Epidemiol Biomarkers Prev 21:895-904

15. Parra-Blanco A, Gimeno-Garcia AZ, Quintero E, Nicolas D, Moreno SG, Jimenez A, Hernandez-Guerra M, Carrillo-Palau M, Eishi Y, Lopez-Bastida J (2010) Diagnostic accuracy of immunochemical versus guaiac faecal occult blood tests for colorectal cancer screening. J Gastroenterol 45:703-712

16. Sturgeon CM, Hoffman BR, Chan DW, Ch'ng SL, Hammond E, Hayes DF, Liotta LA, Petricoin EF, Schmitt M, Semmes OJ et al (2008) National Academy of Clinical Biochemistry Laboratory Medicine Practice Guidelines for use of tumor markers in clinical practice: quality requirements. Clin Chem 54:e1-e10

17. Church TR, Wandell M, Lofton-Day C, Mongin SJ, Burger M, Payne SR, Castanos-Velez E, Blumenstein BA, Rosch T, Osborn $\mathrm{N}$ et al (2014) Prospective evaluation of methylated SEPT9 in plasma for detection of asymptomatic colorectal cancer. Gut 63:317-325

18. Nichita C, Ciarloni L, Monnier-Benoit S, Hosseinian S, Dorta G, Ruegg C (2014) A novel gene expression signature in peripheral blood mononuclear cells for early detection of colorectal cancer. Aliment Pharmacol Ther 39:507-517

19. Huang Z, Huang D, Ni S, Peng Z, Sheng W, Du X (2010) Plasma microRNAs are promising novel biomarkers for early detection of colorectal cancer. Int J Cancer 127:118-126
20. Parikh NI, Vasan RS (2007) Assessing the clinical utility of biomarkers in medicine. Biomark Med 1:419-436

21. Tanaka T, Tanaka M, Ishigamori R (2010) Biomarkers for colorectal cancer. Int J Mol Sci 11:3209-3225

22. Holten-Andersen MN, Christensen IJ, Nielsen HJ, Stephens RW, Jensen V, Nielsen OH, Sorensen S, Overgaard J, Lilja H, Harris A et al (2002) Total levels of tissue inhibitor of metalloproteinases 1 in plasma yield high diagnostic sensitivity and specificity in patients with colon cancer. Clin Cancer Res 8:156-164

23. Babel I, Barderas R, Diaz-Uriarte R, Martinez-Torrecuadrada JL, Sanchez-Carbayo M, Casal JI (2009) Identification of tumor-associated autoantigens for the diagnosis of colorectal cancer in serum using high density protein microarrays. Mol Cell Proteomics 8:2382-2395

24. Poinot-Chazel C, Portier M, Bouaboula M, Vita N, Pecceu F, Gully D, Monroe JG, Maffrand JP, Le Fur G, Casellas P (1996) Activation of mitogen-activated protein kinase couples neurotensin receptor stimulation to induction of the primary response gene Krox-24. Biochem J 320(Pt 1):145-151

25. Souaze F, Viardot-Foucault V, Roullet N, Toy-Miou-Leong M, Gompel A, Bruyneel E, Comperat E, Faux MC, Mareel M, Rostene W et al (2006) Neurotensin receptor 1 gene activation by the Tcf/beta-catenin pathway is an early event in human colonic adenomas. Carcinogenesis 27:708-716

26. Sgourakis G, Papapanagiotou A, Kontovounisios C, Karamouzis MV, Dedemadi G, Goumas C, Karaliotas C, Papavassiliou AG (2014) The combined use of serum neurotensin and IL-8 as screening markers for colorectal cancer. Tumour Biol 35:5993-6002

27. Parmeggiani D, Avenia N, Gubitosi A, Gilio F, Atelli PF, Agresti M (2011) Additional prognostic factors in right colon cancer staging. Updates Surg 63:155

28. Lech G, Słotwiński R, Słodkowski M, Krasnodębski IW (2016) Colorectal cancer tumour markers and biomarkers: recent therapeutic advances. World J Gastroenterol 22:1745-1755 